\title{
RESPUESTA A MARIO CESAREO
}

\author{
POR \\ JOHN BEVERLEY \\ University of Pittsburgh
}

No puedo responder adecuadamente a todas tus observaciones - a veces muy pormenorizadas-sobre Against Literature. Me limitaré entonces a una respuesta global. Primero quiero aclarar mi intención en hacer el libro. Como percibes, se trata de una intervención política e epistemológica a la vez. Mi deseo era, por una parte, llevar el proyecto de "democratización radical", perfilado por Ernesto Laclau y Chantal Mouffe a nuestro campo de trabajo. Sin embargo, el libro era en cierto sentido también una simple declaración de fe, una manera de describir a donde he llegado - where I'm at - después de treinta años, más o menos, como crítico literario y profesor de literatura.

Para muchos de nosostros (para mí en particular, por lo menos), nuestro compromiso vivencial con la literatura se relaciona con la pérdida o el desplazamiento de una fe religiosa. Como se sabe, la literatura representa en la modernidad burguesa precisamente la secularización del impulso religioso: de allí su función como representación y medio a la vez de esa modernidad. Creo que puedo resumir mi postura de la siguiente manera entonces: he pasado de ser un creyente a un agnóstico de la literatura. Pregunto: ¿Es qué tengo el deber, como el San Martín Bueno de Unamuno, de seguir predicando algo que ya no creo, porque creemos que es útil que ellos lo creen? Hace tiempo que no creo en Don Quijote, por ejemplo - para decir la verdad, nunca me gustó del todo. Pero cuando enseñó a Don Quijote siento la obligación de enseñarlo como si fuera todavía un texto "canónico" - recupero el sentido original, religioso de esa palabra - es decir como algo que tiene una autoridad propia como texto, algo a la vez divertido y profundo, lleno de lecciones para mí y para mis alumnos, algo que pide urgentemente y posibilita nuevas "lecturas". Acabo de ver, por ejemplo, una colección de ensayos psicoanalítico-feministas sobre Cervantes editada por Ruth El Saffar y Diana de Armas. Lo que pasa es que los ensayos -el "suplemento" en el sentido que la descontrucción da a ese término-me interesan a veces más que los textos de Cervantes. En la crítica moderna - pienso por ejemplo en Barthes - se invierte la relación entre literatura y discurso crítico; el texto original parece más un pretexto (o pre-texto) para demostrar el ingenio y las preocupaciones actuales del crítico. La crítica asume el lugar de privilegio antes ocupado por la literatura.

Pero si digo esto, si hago un lectura negativa del Quijote como tal -es decir, precisamente el tipo de lectura que el mismo Cervantes hizo de las novelas de caballería o de la novela pastoril - si muestro mi propio agnosticismo ante su autoridad cultural, tengo la sensación que no estoy cumpliendo con mi deber, que estoy cayendo en una especie de 
heteredoxia. Sin embargo, la única manera en que puedo leer y enseñar hoy a Don Quijote es como algo anacrónico, algo que ha perdido su "placer de texto", para recordar el concepto de Barthes, algo que se ha vuelto en cierto sentido "ileible", unreadable (perdóname el neologismo, que debo a Goffredo Diana y Desiderio Navarro). Es decir, tengo que leer al Quijote contra sí mismo, "contra la literatura".

Harold Bloom no tiene este problema -me refiero a su nuevo libro The Western Canon-y, desde una posición política y ética muy distinta, tampoco lo tienes tú, si entiendo bien tus preocupaciones. Tú y Bloom no tienen este problema porque siguen siendo creyentes. Para un creyente los pormenores de un (o el) texto canónico son fascinantes y vivencialmente cruciales; para un no-creyente, sin embargo, el texto ha perdido esa capacidad de fascinación, y puede ser recuperado solamente a través de una arqueología, en el sentido que Foucault da a ese término. No soy un creyente, pero todavía estoy en la literatura: es decir, todavía es el campo que define tanto mi interés profesional como mi compromiso vivencial. Por eso, me defino como un agnóstico y no un ateo de la literatura, y el libro se titula contra la literatura en vezde más allá de la literatura, beyond literature. Beyond literature indicaríaunatransición hacia algo como Estudios Culturales, pero, aunque me siento atraído en esa dirección —estoy colaborando actualmente un estudio transdisciplinario sobre la ciudad de Miamipersonalmente no veo aEstudios Culturales como lasolución a los problemas que enfrentamos hoy en el campo literario. Me parece más bien el resultado de cierto "imperialismo" del campo literario sobre el terreno de las formas culturales populares y subalternas propiamente dichas.

Creo detectar una aporía en el mismo cuestionamiento que haces de mi posición: como señaló Paul de Man, es quizás el destino inevitable de cualquier acto discursivo complejo. Por un lado, dices que tengo una "concepción letrada" de la literatura que "conlleva un vaciamiento histórico y una reconstitución discursiva desde una lógica primermundista". En particular, insistes que dejo al lado otras posibilidades de literatura que no corresponden a "la literatura canónica de las humanidades": vgr. la literatura de cuadros, el periodismo, la literatura de bosillo, el folletín, la tradición oral, etc. (Es interesante observar que Neil Larsen hace una crítica parecida de Against Literature en su nuevo libro, Reading North by South, donde dice que mi concepto de la literatura se refiere esencialmente a la literatura vanguardista, no a la literatura en general; está de acuerdo conmigo en la crítica de esa literatura, pero en su lugar propone una vuelta a un realismo social de corte lukacsiano.)

Por otro lado, haciendo referencia a una observación mía en el prefacio del libro, sugieres que "al construir lo literario como 'zona de contacto' sujetas el discurso crítico a los mismos problemas hermenéuticos que te propusieras superar". Hay una paradoja aquí, porque era precisamente para evitar el "vaciamiento histórico" de que hablas (es decir, la construcción de la literatura como un categoría ideal fuera de un contexto inmediato de producción y recepción) que había recurrido a la idea de Mary Pratt del texto como "contact zone"-debo aclarar que estaba aludiendo no a su definición del concepto en Imperial Eyes que citas, sino al artículo de Pratt sobre Gloria Anzaldúa y otras escritoras latinas, "Arts of the Contact Zone," que apareció en la revista del MLA, Profession 91 (1991). Había escuchado en varias ocasiones caracterizaciones de mi posición como "nihilista" - creo que tú tampoco estás muy lejos de esto en tu visión de Against Literature - y quería dejar una apertura - leave the door open, comodecimos en inglés - para otras posibilidades de articulación literaria, precisamente en la dirección de esa visión menos "canónica", menos académica de la literatura que 
propones. Hize esta concesión en particular como respuesta al libro Culture and Imperialism de Edward Said, que salió cuando estaba corregiendo la pruebas de Against Literature. Después de someter la "Great Tradition" de la novela occidental a una inquisición minuciosa por sus conexiones con el colonialismo y el imperialismo, Said termina el libro proponiendo la apropiación y refuncionalización de esa tradición como la base necesaria de un nuevo humanismo poscolonial, "another way of telling", en sus palabras. En ese momento, también estaba leyendo a Anzaldúa, concretamente Borderlands/La frontera, y, motivado por el artículo de Pratt y las preocupaciones de Said, se me ocurrió preguntar, ¿Qué pasa con la literatura en condiciones de una desterritorialización posmoderna, donde pierde su rol central en la formación de una cultura nacional, pierde su relación con un estado nacional (supuestamente) lingüísticamente homógeneo, pierde su relación con el falogocentrismo? ¿Es qué Anzaldúa representa la posibilidad de una literatura otra? Y en ese caso, ¿cómo tendría que modificar el argumento del libro?

Tu reacción a lo que fue algo dicho de paso me hace pensar, sin embargo, que quizás concedí demasiado con esto de "contact zone". Creo que, de hecho, Anzaldúa et al. no superan los límites o funciones de la ciudad letrada. También creo como tú que hay que distinguir entre un aspecto descriptivo y otro normativo del concepto de zona de contacto. Como concepto normativo me parece que tiene de hecho, como tu señalas, el mismo inconveniente - la persistencia de un idealismo estético vanguardista- que otros anteriores, como (para mencionar algunos de las más conocidos en nuestro campo) el "mestizaje cultural" de Pedro Henríquez Ureña, la "transculturación narrativa" de Rama (para mí, La ciudad letrada es en cierto sentido una autocrítica de Rama de su propio concepto), el "neobarroco" de Sarduy, o las hibridizaciones poscoloniales de Homi Bhabha o Néstor García Canclini. Como un concepto descriptivo, sin embargo, "contact zone" es útil para hablar de las contradiciones en el escenario concreto - lo que Tony Bennett llama la "formación [social] de la lectura" (reading formation) - que esta involucrado en actos de creación o recepción literaria (vienen a ser en cierto sentido lo mismo, ¿no?) No es en el texto en sí donde está el problema, en otras palabras, sino en su capacidad de ser utilizado por tal o cual persona o en relación a tal o cual proyecto social. Pero insisto que esta posiblidad de "recepción" es algo que no puede separarse del todo del rol de la crítica literaria y de la institución académica en la conformación de lo literario.

No hay que situarse en un futuro revolucionario (o como es más probable, norevolucionario), por lo tanto, para entender el problema de la relación de la literatura con la democratización. Meparece que hay dos preguntas distintas (aunque relacionadas) involucradas aquí. La primera es, citando tu propio comentario, si "una negación de lo literario haría posible su reemplazo por otras formas culturales", ya que la literatura es "el resultado de una necesidad política que jamás sería satisfecha por estas otras formas de cultura”. Es, como indicas, el problema de Estudios Culturales o del testimonio: el hecho de que pueden entrar a nuestro ámbito sólo a través de lo que llamas acertadamente su "literaturización".

La segunda pregunta es si mi supuesta "reducción del espacio social a su espectacularidad universitaria" en el argumento del libro no supone una operación idéntica a la textualización de la experiencia social por parte del discurso crítico posestructuralista. Es una buena pregunta, porque indica que hay otros espacios - no académicos - para la literatura, y otras prácticas, también no-académicas, de la literatura. Pero la pregunta también involucra una 
diferencia clave en la manera en que pensamos la relación entre la política grosso modo y lo que Althusser llamaba una práctica ideológica. Creo que no das suficiente atención al comienzo del libro donde me solidarizo con la declaración de Gayatri Spivak, cuando dice "I don't say that I'm just a literary critic. I say I am a literary critic". Como una persona comprometida con la izquierda, he tenido cierta militancia extra-académica en mi vida: en el movimiento contra la guerra de Vietnam, en varios partidos o proto-partidos socialistas, en sindicatos, en comités de solidaridad, etc. Pero Against Literature no es una representación o una teoría de eso. Es un libro por un académico para académicos de la literatura: en otras palabras, un libro profesional. Haces bien en preguntar, ¿Qué son los límites de nuestra actividad profesional? Pero la meta del libro es tratar de pensar que podemos hacer dentro de esos límites, que, por supuesto, son los límites de nuestra vidas (y efectividad) profesionales. Mi modelo - lo declaro en el libro- es la idea de Althusser de un "antihumanismo teórico", y lo que hago es, por lo tanto, "solamente" teoría. Against Literature no es (no quiere ser) La declaración de los derechos del hombre, o ¿Qué hacer?, o Revolución en la revolución. Sin embargo, si tengo razón en pensar que muchas (¿todas?) prácticas de hegemonía y contra hegemonía en el mundo actual pasan o están afectadas de una manera u otra por la universidad, entonces un trabajo "solamente" teórico-académico puede tener "efectos" en otras instancias sociales (tuvieron efectos - por bien o mal- la práctica crítica de Althusser y su grupo). La diferencia es entre ver la universidad como un lugar donde se representan las luchas sociales o como un lugar atravesado por esas luchas.

Yo entiendo en particular que la literatura es una de las prácticas ideológicas en que se ha formado el sujeto burgués-patriarcal moderno, y que surge en una relación concreta muy cercana con el humanismo académico, es decir, con la crítica y la pedagogía literaria. Es en nombre de la "plenitud" de este sujeto que se determina la subalternidad de los demás. Por lo tanto, una negación de la literatura, aunque por supuesto no nos libera de lo negado, si puede contribuir a desmantelar la distinción que existe - mantenida entre otras cosas por el sistema de educación y discriminación cultural- entre élite y las clases populares o subalternas (siguiendo el ejemplo de Ranajit Guha, el fundador del Grupo de Estudios Subalternos, empleo estos términos como sinónimos). No creo que la liberación o el ejercicio de plenos derechos civiles de estas clases o grupos debe esperar su "educación" o que su integración a la ciudad letrada debe ser la condición - jurídica o extra-jurídica- de su plena ciudadanía.

Mi preocupación con la música, que sirve como conclusión al libro, depende de dos consideraciones relacionadas con este problema: uno, que la música en todas sus formas "arte mujeril", según se clasificaba en el siglo XIX europeo- ha tenido una relación subalterna con respeto a la literatura en la institucionalidad burguesa, y me interesa invertir esa relación; dos, que la música, no a pesar de su comercialización (como pensaba Adorno y la escuela de Frankfurt), sino en parte precisamente a causa de esa comercialización, sigue siendo un espacio de resistencia y contra-hegemonía popular. En ese sentido no estoy de acuerdo con tu observación que "el materialismo consumista se encuentra en una posición antagónica al materialismo ecológico y religioso: su incapacidad de ir más allá del reino de las mercancías se expresa teóricamente en el rechazo de toda alegoría sentimental, de toda verdad". Para mí, la gran lección de Walter Benjamin (y también de Michel de Certeau) es todo lo opuesto: que sí hay una relación entre "materialismo consumista" y las posibilidades de "redención". Como dice Canclini en el título de uno de sus ensayos, "el consumo también sirve para pensar". 
Es importante recordar en este contexto una referencia clave que ofrezco en apoyo de mi argumento: el análisis que Julio Ramos hace en su libro Desencuentros de la modernidad de la manera en que Martí experimenta con muchaambivalencia la cultura demasasnorteamericana en los ensayos de Escenas norteamericanas. Es quizás una posición menchevique, pero me parece 1) que la cultura de masas burguesa moderna es, en general, más democrática que la cultura señorial y religiosa feudal, entre otras cosas porque la lógica del mercado le obliga a responder más directamente al flujo de la demanda y el gusto popular (dejo para otra ocasión el problema de la configuración de ese gusto), y 2 ) que elementos de superestructuras feudales o semi-feudales siguen teniendo mucho peso en la cultura hispana e hispanoamericana. Por supuesto, me refiero al feudalismo en particular y no a formaciones sociales precapitalistas en general. Me parece que muchas de estas formaciones son democráticas e igualitarias (vgr. el ayllu andino celebrado por Mariátegui, o elementos del "comunismo primitivo" de las comunidades indígenas), pero no el feudalismo, la esclavitud, los sistemas de despotismo agrario (indígenas o coloniales), o las estructuras oligárquicas impuestas en el período nacional. En ese sentido, y tomando en cuenta la conexiónn cercana entre la literatura escrita y la formación de los estados nacionales en el siglo XIX, debemos por lo menos considerar la posibilidad que el "arielismo" literario en América Latina -la creencia en el papel redentor de la literatura y en la relación entre valores literarios y "espíritu" nacional- tenga alguna relación con la persistencia de estas estructuras.

Sin embargo, repito que no veo a Estudios Culturales en su institucionalización académica actual como una resolución teórica de esta problemática. Por el contrario, comparto plenamente tus observaciones sobre la nueva función del "scholar" humanístico en relación a la globalización como "compilador, exégeta y sintetizador de la heteroglosia social". En particular, en la segunda parte del capítulo dos de Against Literature, "The Formation of the Ideology of the Literary", hago una crítica explícita de Stephen Greenblatt y el Nuevo Historicismo norteamericano como ejemplo de una práctica posmoderna de las humanidades, con efectos político-ideológicos ambiguos. Me sorprende que no hagas referencia a esa discusión; el problema puede ser que mucha gente pasa por alto este capítulo, quizás porque comienza con una close-reading un poco aburrida (es decir, literaria) de un soneto canónico de Garcilaso. A pesar de tu sentido de que mi texto es un "pastiche" posmoderno, sin embargo, este capítulo tiene un lugar necesario en la lógica de mi argumento. Me he dado cuenta que todos mis libros hasta ahora han tenido una forma esencialmente historicista. El libro que anticipa a Against Literature, por ejemplo, fue una colección de ensayos que publiqué a mediados de los ochenta con el título Del Lazarillo al Sandinismo. Against Literature bien podría llevar el subtítulo "de Garcilaso a Cultural Studies". Sin embargo, reconozco que también pongo en crisis en el libro el modelo de una "narrativa maestra" historicista: en ese sentido, tienes razón en verlo como un "naufragio" literario-conceptual. Del Lazarillo al Sandinsimo concluye con la idea de una nueva etapa histórica inaugurada por la revolución sandinista, que sería algo así como una continuación dialéctica, en el campo de la literatura, de una lógica histórica necesaria subyacente; por contraste, el contexto de Against Literature es la pérdida de hegemonía por los sandinistas en las elecciones de 1990 y la crisis general del marxismo, y de allí un sentimiento agudo de la necesidad de "empezar de nuevo". En ese sentido, Against Literature testimonia una pérdida de fe no sólo en la literatura, sino también en la historia $\longrightarrow$, más exactamente, en cierta concepción teleológica de la historia — la 
Historia con mayúsculas - relacionada, aun en sus modalidades supuestamente "marxistas" o socialistas, con la configuración de una modernidad esencialmente burguesa y con el perfeccionamiento del estado nacional (en la perspectiva de Guha y el Grupo de Estudios Subalternos, lo subalterno es precisamente lo que "interrumpe" la narrativa de formación y perfeccionamiento del estado).

Como indicas, el corazón del libro son los dos capítulos sobre testimonio, "The Margin at the Center" y "Second Thoughts on Testimonio", en que pretendo imaginar qué sería una lógica de representación no dependiente de una "narrativa maestra" de modernización y estatización -es decir, no dependiente en última instancia de la literatura y de lo que Rama entendía por la ciudad letrada. Te preocupa, sin embargo, mi tendencia a otorgar un poder de gestión - agency — a la voz "testimonial" en sí que aparentemente niego a una política de "representación" más convencional (de una literatura progresista, de partidos, movimientos, el estado revolucionario, etc.). En particular, preguntas si " ¿no puede el habla [testimonial] misma ser un hecho constituyente que, mediante su emplazamiento, construya una subjetividad extraliteraria, organizada política e institucionalmente ... mediante un programa, tácticas, y estrategias que entran en conflicto con la organización canónica de la realidad?"

No se puede dudar que el testimonio es más que una expresión espontánea de un sujeto subalterno, sin la mediación de "intelectuales solidarios" (para emplear el concepto de Hugo Achugar), organizaciones, redes de solidaridad, etc. Como señalas, por ejemplo, su canonización como género es a través de la política cultural del estado revolucionario cubano. Pero en cierto sentido el testimonio también transciende esta "institucionalidad", y a veces entra en una relación dialógica y hasta antagónica con sus normas. Un ejemplo serían los testimonios de personas reprimidas por la revolución cubana por razones de life style: vgr. los homosexuales que aparecen en la película de Nestor Almendros. Por otro lado, para recordar un texto canónico de la revolución, se piensa realmente que el misantrópico y solitario Esteban Montejo de Biografia de un Cimarrón - y esa misantropía era vista por el propio Montejo como una actitud necesaria para mantenerse libre de la esclavitud - ies el modelo del "hombre nuevo" de la revolución? Pienso más bien que Barnet, concientemente o inconcientemente, quería dar voz a través del testimonio de Montejo a posiciones sociales subalternas todavía marginadas o "representadas por" la instancia "superior", paternalista del estado revolucionario (es decir, concretamente de su aparato pedagógico-cultural). Sería interesante en ese sentido leer a Biografia de un Cimarrón hoy como una alegoría de la liminalidad del sujeto gay "dentro de la revolución", donde, por supuesto, todo noera posible: es decir, en cierto sentido la situación del propio Barnet.

¿Cómo entender la dialéctica entre institucionalidad política, subalternidad y el testimonio, entonces? Mi estudiante Goffredo Diana esta haciendo una tesis sobre este problema, basándose en el caso cubano en particular, y promete aportar una serie de nuevos elementos de reflexión sobre esta pregunta. Pero me atrevo a sugerir aquí algunas ideas provisionales. El testimonio de la revolución cubana tuvo sus orígenes en textos como las Memorias de la guerra revolucionaria cubana del Che que eran representaciones directas, vivenciales de la guerrilla. Conviene recordar que en su momento de auge la guerrilla no fue exactamente el "estado revolucionario" o un partido político en un sentido convencional; más bien se asemejaba de algún modo a la famosa micropolítica de Foucault y Deleuze y Guattari. Después del triunfo de la lucha armada, el género funcionó - y debía haber seguido 
funcionando-para introducirvoces todavía marginadas en la ciudad letrada posrevolucionaria - esto fue, por ejemplo, el proyecto de Barnet. Una cosa es que un escritor de la élite criolla comprometida con la revolución como Alejo Carpentier escriba la historia de un sujeto negro semi-proletario (El reino de este mundo); otra cosa es que ese sujeto tenga la posibilidad de narrar su propia historia, aun con todas las "mediaciones" que implica la elaboración de un testimonio. Pero en esas narraciones quizás aparezcan elementos que no agraden a la "oficialidad" revolucionaria (o, lo que viene a ser casi lo mismo, al interlocutor letrado que sirve como compilador del testimonio): quizás el narrador es marihuanero, por ejemplo; quizás es negro y aunque apoya a la revolución siente que no ha eliminado del todo el problema del racismo; quizás es gay; quizás le gusta el Heavy Metal norteamericano en vez de la Nueva Trova "políticamente correcta" o la salsa; quizás -iheterodoxia mayor! — no le gusta Martí. Quizás todas estas cosas.

Lo que hemos aprendido de la crisis de los estados socialistas existentes, sin embargo, no es tanto la imposibilidad del socialismo sino que una "democraciapopular" — para recordar la denominación oficial de estos regímenes- debe ser un estado concretamente de las clases populares, no algo ejercido para (en nombre de) ellos por personas con una formación cultural radicalmente distinta en muchos aspectos. Si a la gente le gusta hacer compras, shopping, el socialismo debe ser más shopping, ¿no?, entre otras cosas, porque la privación económica es precisamente lo que impone una lógica capitalista de explotación de la fuerza de trabajo. Y si hay conflictos entre prioridades, si hay que escoger entre shopping y desarrollo industrial, centralización de distribución o mercados libre campesinos, debe haber unamanera plenamente democrática de decidir entre ellas, porque no es evidente de antemano que una de estas alternativas es superior a la otra.

Aquí es útil recordar el concepto de Mao de "las contradicciones en el seno del pueblo". El ocaso del testimonio cubano - y no hay duda que la forma esta casi totalmente agotada en Cuba hoy - se debe a que perdió la capacidad de representar estas "contradicciones en el seno del pueblo". El testimonio sirvió en ese sentido para institucionalizar un imaginario revolucionario, a través por ejemplo de su promoción por el premio Casa de las Américas, pero no sirvió a la revolución, que depende para su fuerza de "poner arriba lo que esta debajo". Mi interés en el testimonio entonces no pasa por la experiencia cubana, sino por el nuevo auge de la forma en los ochenta; coincide no con la época "heroica" de la revolución, sino con su situación precaria de hoy —es decir, con su debilitamiento como símbolo y dirección general a la vez de una "narrativa maestra". No es que he perdido fe en la posibilidad revolucionaria, aunque tengo que imaginarla de una forma nueva. Tampoco pienso, como sugieres a veces, que podemos superar a través de una política de "dar voz" a lo subalterno el problema de la representación, tanto en el sentido de hablar por como de hablar de. Sin embargo, me interesa lo que pasa con nuevas prácticas de representación como el testimonio que tienen una relación si no abiertamente antagónica, por lo menos problemática con la construcción canónica de la literatura.

Creo que podemos luchar al lado de Rigoberta Menchú o del subcomandante Marcos (sabemos hoy que Marcos fue de hecho uno de nosotros, un profesor althusseriano de comunicaciones a comienzos de los ochenta en la Universidad Autónoma de México), pero entonces ya no estaríamos en la universidad o la escuela. ¿Cómo podemos luchar con Menchú o los zapatatistas estando en la universidad o la escuela, siguiendo nuestra agenda, que - 
aunque puede involucrar una coincidencia de intereses - no es exactamente la misma agenda de Menchú y Marcos y las gentes que ellos representan directamente? Esta me parece ser la pregunta que introduce el testimonio, pero lo introduce precisamente en el contexto de su incorporación en la academia, no aparte de esa incorporación, como si sus "efectos" discursivos tuviesen lugar en otro espacio. No dudo que hay muchas prácticas literarias contestatarias fuera de - para recordar tus palabras- "la literatura canónica de las humanidades". Pero si nuestra función académica consiste solamente en describir estas prácticas, no creo que esto tenga en sí un efecto muy radicalizador: más bien, parece un nuevo tipo de costumbrismo o, peor aun, un esfuerzo para "restituir" en el campo de las humanidades los "daños" culturales, económicos, etc. que constituyen lo subalterno en el nivel social opuesto al nuestro. Pregunto: ¿no hace falta para ampliar el espacio y la autoridad de estas prácticas extra-académicas precisamente una negación crítica de la autoridad del canon?

Sin embargo, no creo que he terminado, como dices, "reemplazando lo literario por la cultura de masas y la vanguardia por el posmodernismo, dejando silenciados a los grupos subalternos desde cuyas perspectivas intentabas teorizar [esta] negación". Otra vez, me parece que Estudios Culturales corre el peligro de ser una mera transposición de la ideología de lo literario a la cultura de masas y de constituirse como una nueva forma de "capital cultural", para recordar el concepto de Bourdieu. Hace falta un PhD para lograr un conocimiento suficientemente complejo para participar plenamente -es decir, con una conciencia"crítica"en el estudio académico de la cultura de masas, y evidentemente esta no es la forma en que las "masas" experimentan esta cultura como regocijo o la emplean en un sentido contrahegemónico.

Creo que la clave de tu descontento con Against Literature está en otro lugar. La versión original de tu intervención culminó en una visión - "en contraposición a tu antiliteratura," decías explícitamente- " "de un entendimiento del ser humano somo ser génerico, como naturaleza pensándose a sí misma". La literatura sería para ti la (o una) expresión necesaria de esa "naturaleza". Veo que esta frase ha desaparecido en la versión actual, quizás por un exceso de "humanismo", pero creo que su lógica todavía está presente en tu argumento de algún modo. Me parece que esta lógica lleva en la misma dirección que el pensamiento de Paulo Freire, que - a pesar de su compromiso indudable con los procesos de democratización y justicia social - para mí es esencialmente una versión nueva del proyecto pedagógico decimonónico de Sarmiento o Bello. Quedamos en la dialéctica del maestro y el esclavo. Nosotros - los maestros, artistas, escritores, críticos, técnicos- tenemos pleno aceso al saber y a la subjetividad. Somos "sujetos" con poder de gestión (manejamos sistemas de autoridad como la escritura y la literatura). Ellos, de una forma u otra, necesitan aprender de nosotros, o, lo que es más díficil aun, ser como nosotros, para llegar a tener una subjetividad plena. Pero este requisito postergaría indefinidamente, aun cuando se concede - como Freire hace - una autoridad propia a las culturas subalternas y aun después de muchas revoluciones y muchas campañas de alfabetización, el acceso al ejercicio de la ciudadanía y el gozo de los derechos civiles por parte de la mayoría de los seres humanos, en nombre de una visión de su posible "mejoramiento" o "liberación" pedagógica. Yo estoy buscando algo que podría escapar a esta lógica. Por eso me niego a pensar que tengo algo indispensable para enseñar. A la vez, sigo enseñando.

Debo añadir una consideración última, propiamente "estética" si se quiere. Me culpas varias veces de ser demasiado "formalista" en mi argumento; dices, por ejemplo, "Una 
perspectiva menos formalista tendería a ver en lo literario una arena más donde se ensayan, desarrollan y resuelven los conflictos propios del momento histórico". De acuerdo: la literatura es sólo "una arena más"; no hay que darle un privilegio especial. Pero también es una arena, y lo que aprendí y retengo de los formalistas es su explicación de como -en términos materiales-la literatura ensaya, desarrolla, etc. "los conflictos propios del momento histórico". Si es verdad, como los formalistas pensaban, que el efecto estético reside esencialmente en la experiencia de ostranenie o desfamiliarización (aunque tenemos nuevas maneras de conceptualizar en que consiste esto: por ejemplo, lo que se ha llamado el "efecto testimonial"), entonces la historia literaria-y no sólo la historia de la literatura culta o canónica - depende esencialmente de una lógica de negación. Creo que la literatura existe hoy sólo en su negación. De allí que Against Literature sea en cierto sentido también una defensa de la literatura. 
